\title{
Application of the daily egg production method to Baltic sprat
}

\author{
H. Haslob ${ }^{\mathrm{a}, *}$, H. Hauss ${ }^{\mathrm{a}}$, H.H. Hinrichsen ${ }^{\mathrm{a}}$, R. Voss ${ }^{\mathrm{b}}$, U. Böttcher $^{\mathrm{c}}$, G. Kraus $^{\mathrm{d}}$ \\ a Helmholtz Centre for Ocean Research (GEOMAR), Düsternbrooker Weg 20, 24105 Kiel, Germany \\ ${ }^{\mathrm{b}}$ Christian Albrechts Universität zu Kiel, Department of Economics, Wilhelm Seelig Platz 1, 24118 Kiel, Germany \\ ${ }^{\mathrm{c}}$ Heinrich von Thünen Institute for Baltic Sea Fisheries, Alter Hafen Süd 2, 18069 Rostock, Germany \\ ${ }^{\mathrm{d}}$ Heinrich von Thünen Institute for Sea Fisheries, Palmaille 9, 22767 Hamburg, Germany
}

\section{A R T I C L E I N F O}

\section{Article history:}

Received 8 September 2011

Received in revised form 5 March 2012

Accepted 18 March 2012

\section{Keywords:}

DEPM

Sprattus sprattus

Stock assessment

Egg mortality

\begin{abstract}
A B S T R A C T
Baltic sprat (Sprattus sprattus balticus, Schneider 1908) is a key species in the Baltic Sea ecosystem, where it is the most abundant planktivorous fish. In the present study, we applied the daily egg production method (DEPM) for the years 1999-2008 to estimate the size of the stock component reproducing in the Bornholm Basin, a major spawning ground for sprat and cod. This is the first study assessing this stock with a fishery independent egg production method for a consecutive time series of ten years. DEPM stock size estimates were compared with those obtained by a multi species virtual population analysis for the same stock component and results from an acoustic survey. In general, the results obtained by the DEPM were in the same order of magnitude compared to the other methods and most similar to the acoustic estimate. However, in some years differences between methods were substantial. With respect to previous egg production methods to assess Baltic sprat stock components our approach takes several aspects into account which were ignored before, e.g. effect of ambient temperature range on sprat egg stage duration and mortality and interannual variability of adult stock parameters. Since the accurate determination of the daily spawning fraction bears major uncertainties, different scenarios were tested for this parameter. Least deviation compared to the other assessment methods was obtained when using a daily female spawning fraction of $24 \%$, which corresponds well to values described in literature. The applicability of the DEPM to Baltic sprat was clearly demonstrated. Thus, it can serve as valuable tool for the estimation of Baltic sprat stock sizes independent of data obtained from commercial fisheries.
\end{abstract}

(c) 2012 Elsevier B.V. All rights reserved.

\section{Introduction}

The daily egg production method (DEPM) was demonstrated to be an adequate tool to estimate the spawning stock biomass of pelagic fish species with indeterminate fecundity and multiple spawning (Parker, 1980; Lasker, 1985). The DEPM has been applied for numerous stocks around the world (Alheit, 1993; Stratoudakis et al., 2006). One advantage of egg production methods is their independence of catch data from commercial fisheries, which is often biased due to: (i) misreporting of catches, (ii) discards, or (iii) specific fishing patterns. Further, only a single survey during the peak spawning period is necessary to assess the spawning stock biomass via DEPM.

Besides a fishery-independent stock size estimate, the DEPM provides valuable biological data of the stock reproductive

\footnotetext{
* Corresponding author. Tel.: +49 431600 4557; fax: +49 4316004553. E-mail addresses: hhaslob@geomar.de (H. Haslob), hhauss@geomar.de (H. Hauss), hhinrichsen@geomar.de (H.H. Hinrichsen), voss@economics.uni-kiel.de (R. Voss), uwe.boettcher@vti.bund.de (U. Böttcher), gerd.kraus@vti.bund.de (G. Kraus).
}

potential, which is often not taken into account in standard assessment methods, e.g. the fecundity and spawning fraction of the stock as well as the distribution, abundance and survival of the early life stages. Therefore, the DEPM is considered a cost and time effective assessment method that accounts for the influence of various processes acting on biological traits from the oocyte development to the pelagic egg phase (Stratoudakis et al., 2006). Thus, egg production methods additionally provide new insights into the reproductive dynamics of the assessed species and its interaction with the environment (Somarakis et al., 2004).

Some issues related to the use of DEPM remain. It can only be applied during the spawning season. Also, two major methodological challenges remain: first, in order to assess the whole population it has to be assured that the complete spawning area is covered by the ichthyoplankton survey and spatial patchiness in egg distribution is resolved sufficiently. Secondly, a crucial source of uncertainty in applying the DEPM has been identified in the determination of the daily spawning fraction of female fish (Stratoudakis et al., 2006; Ganias, 2012).

Baltic sprat (Sprattus sprattus balticus, Schneider 1908) is a key species in the Baltic Sea ecosystem, as it is the most abundant planktivorous fish species. Besides its ecological importance sprat 
Table 1

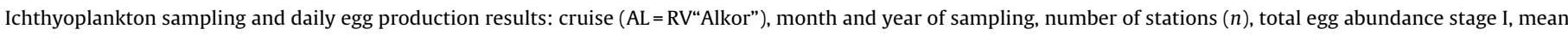

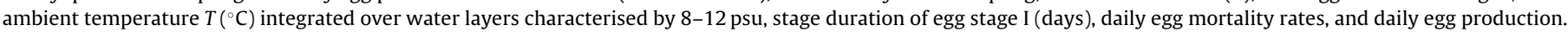

\begin{tabular}{|c|c|c|c|c|c|c|c|c|c|c|}
\hline \multirow[t]{2}{*}{ Cruise } & \multirow[t]{2}{*}{ Month } & \multirow[t]{2}{*}{ Year } & \multirow[t]{2}{*}{$n$} & \multirow{2}{*}{$\begin{array}{l}\text { Total abundance } \\
\text { stage } \mathrm{I}\left(\times 10^{12}\right)\end{array}$} & \multirow{2}{*}{$\begin{array}{l}\text { Mean ambient } \\
T( \pm \text { SD })\end{array}$} & \multirow{2}{*}{$\begin{array}{l}\text { Stage I } \\
\text { duration }\end{array}$} & \multicolumn{2}{|c|}{ Daily egg mortality } & \multicolumn{2}{|c|}{ Daily egg production } \\
\hline & & & & & & & $z( \pm \mathrm{SE})$ & $p$ & $P_{0}\left(\times 10^{12} \pm \mathrm{SE}\right)$ & $p$ \\
\hline AL143 & June & 1999 & 42 & 5.62 & $5.04( \pm 0.83)$ & 3.12 & $0.44( \pm 0.07)$ & $<0.05$ & $3.56( \pm 0.50)$ & $<0.05$ \\
\hline AL161 & May & 2000 & 41 & 1.61 & $4.57( \pm 0.71)$ & 3.30 & $0.14( \pm 0.06)$ & 0.12 & $0.63( \pm 0.15)$ & 0.05 \\
\hline AL182 & May & 2001 & 45 & 3.72 & $4.36( \pm 0.70)$ & 3.37 & $0.20( \pm 0.05)$ & 0.06 & $1.58( \pm 0.28)$ & $<0.05$ \\
\hline AL200 & April & 2002 & 29 & 2.47 & $5.23( \pm 0.93)$ & 3.05 & $0.87( \pm 0.40)$ & 0.16 & $3.38( \pm 2.11)$ & 0.25 \\
\hline AL217 & March & 2003 & 45 & 1.88 & $3.47( \pm 0.72)$ & 3.74 & $0.58( \pm 0.14)$ & 0.06 & $1.48( \pm 0.42)$ & 0.07 \\
\hline AL238 & June & 2004 & 45 & 1.55 & $4.56( \pm 0.67)$ & 3.30 & $0.25( \pm 0.03)$ & $<0.05$ & $0.71( \pm 0.06)$ & $<0.05$ \\
\hline AL258 & May & 2005 & 42 & 1.14 & $4.18( \pm 0.98)$ & 3.44 & $0.21( \pm 0.04)$ & $<0.05$ & $0.48( \pm 0.08)$ & $<0.05$ \\
\hline AL279 & June & 2006 & 41 & 2.61 & $3.15( \pm 0.63)$ & 3.88 & $0.27( \pm 0.03)$ & $<0.05$ & $1.15( \pm 0.10)$ & $<0.05$ \\
\hline AL299 & May & 2007 & 38 & 4.36 & $5.04( \pm 0.39)$ & 3.12 & $0.18( \pm 0.03)$ & $<0.05$ & $1.91( \pm 0.21)$ & $<0.05$ \\
\hline AL318 & April & 2008 & 45 & 3.97 & $5.84( \pm 0.92)$ & 2.84 & $0.20( \pm 0.03)$ & $<0.05$ & $1.77( \pm 0.21)$ & $<0.05$ \\
\hline
\end{tabular}

is heavily exploited. Sprat is regularly assessed by the International Council for the Exploration of the Sea (ICES) as a single stock unit in the entire Baltic (ICES sub-divisions 22-32) using virtual population analysis with an extended survivor analysis (XSA) based on catch data, which is tuned by an acoustic survey conducted in autumn and spring (ICES, 2010a). The calculation of spawning stock biomass (SSB) with this standard method does not take into account observed spatial and temporal variability of reproductive parameters. As comprehensive and coherent investigations on the variability of Baltic sprat maturity are lacking so far (ICES, 2010a), the maturity ogive is kept constant over the entire time series to calculate SSB.

Neglecting biological variability in reproductive parameters can be problematic. Whilst in general more than $90 \%$ of the sprat stock older than 2 years are mature, there is considerable variability in proportion mature sprat within age groups one and two. This may lead to a significant underestimation of sprat SSB in years with a high proportion of young sprat being mature or vice versa. Further, the spawning stock biomass is not calculated sex specific, although observations show that the sex ratio is skewed towards a higher proportion of females with increasing size or age, respectively (Grygiel and Wyszyński, 2003). Another shortcoming of this assessment is that the stock abundance estimates are not provided for stock components inhabiting different areas of the Baltic Sea. As sprat are known to be important predators on eggs of eastern Baltic cod (Köster and Schnack, 1994; Voss et al., 2011), which has its main spawning ground in the Bornholm Basin, it is desirable to estimate the stock size in this particular area.

Several attempts were made in the past to estimate sprat stock sizes in the Baltic Sea by egg production methods. Grauman and Krenkel (1986) estimated the sprat stock covering extensive areas from the Arkona Basin up to the central Gotland Basin. Macarchouk and Yula (2001) and Macarchouk (2007) estimated the sprat stock for the Gotland Basin applying the Hensen-Apstein method (Hensen and Apstein, 1897). However, these authors made many assumptions and simplifications concerning sprat stock structure, especially on fecundity and spawning fraction, two crucial parameters in egg production methods. Kraus and Köster (2004) applied for the first time the DEPM to estimate sprat stock abundance of Baltic sprat. They modified the original DEPM model to calculate the stock size based on fish length classes. Although their study was restricted to one year only, it demonstrated that this method might successfully be applied to Baltic sprat. In this previous DEPM approach on Baltic sprat the effect of ambient temperature on the egg stage duration and egg mortality was not taken into account. Further, the highly stratified hydrography of the Baltic Sea leads to a distinct vertical distribution of fish eggs confined to water layers where eggs obtain neutral buoyancy (Wieland et al., 1994; Nissling et al., 2003). The range in ambient temperature in this water layer will also affect daily egg production estimates, which was assessed in the present study.

In the present study we provide a time series of detailed observations and variability estimates of Baltic sprat reproduction parameters, i.e. sex ratios, maturity ogives, spawning fraction, and batch fecundity. These were combined with total sprat egg production data obtained by ichthyoplankton surveys to assess the stock size of Baltic sprat with a DEPM application, and to evaluate the impact of variability in reproduction parameters on these estimates. For the first time fishery independent stock size estimates were achieved for Baltic sprat as a continuous time-series of ten years 1999-2008 in the Bornholm Basin (ICES sub-division 25). The obtained results were compared with sprat abundance data from acoustic surveys and from an area disaggregated multi-species virtual population analysis (MSVPA).

\section{Materials and methods}

\subsection{Daily egg production from ichthyoplankton surveys}

The abundance of sprat eggs was obtained from ichthyoplankton surveys covering the Bornholm Basin (Table 1 ) on a 45 stations grid $(10.0 \mathrm{~nm} \times 8.5 \mathrm{~nm}$ miles; Fig. 1$)$. Double oblique hauls with a Bongo net (net diameter $=60 \mathrm{~cm} ; 335 \mu \mathrm{m}$ mesh size) were conducted on each station. In some years, not all stations were sampled due to gear failure or bad weather conditions, but a

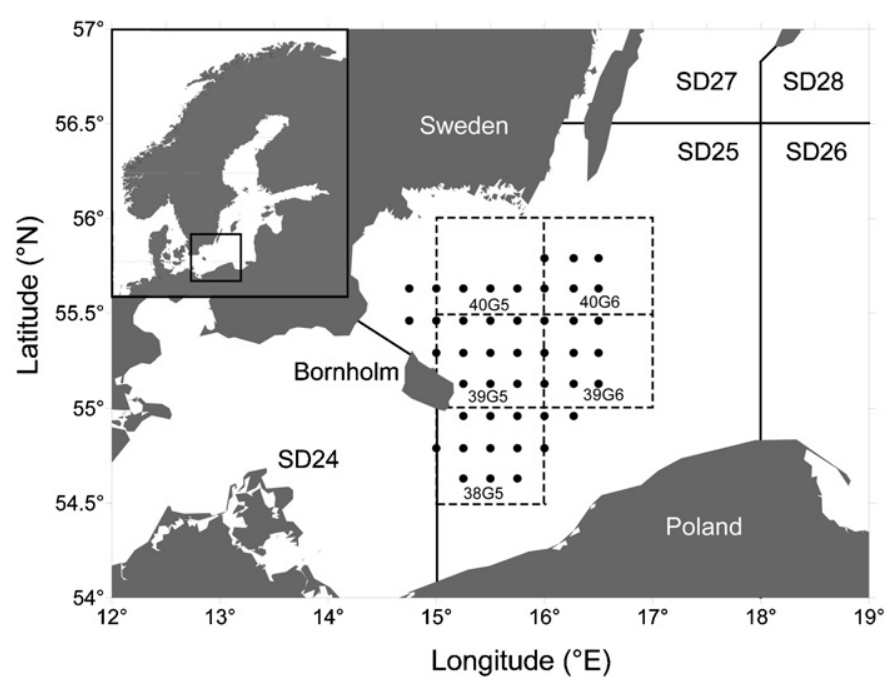

Fig. 1. Investigation area in the south-central Baltic, Bornholm Basin. Dots show positions of stations covered by the ichthyoplankton surveys. ICES sub-divisions and rectangles used for stock abundance calculation from acoustic survey data, and for downscaling MSVPA abundance data are labelled with their code. 
sufficient coverage of the basin was achieved in all years. Samples were preserved in a $4 \%$ buffered formaldehyde seawater solution immediately after sampling. Ichthyoplankton was sorted in the laboratory and sprat eggs were assigned to five stages (Ia, Ib, II, III, IV according to Thompson et al., 1981). For each station the egg abundance was calculated as eggs $\mathrm{m}^{-2}$ (Fig. 2). Because of uncertainties concerning the identification of egg stage Ib, the first two egg stages, la and Ib, were grouped into the egg stage I.

Stage-specific total egg abundance in the area was estimated with an objective analysis (Bretherton et al., 1976). This method is designed for data sets containing relatively low numbers of observations and is able to interpolate over stations where no data are available. It is based on a standard statistical approach, the Gauss-Markov theorem, which gives an expression for the linear least-square error estimate of the variables. This method creates horizontal egg abundance fields by interpolating observed egg abundances onto a regular grid. The analysis uses a spatial isotropic Gaussian covariance function of measurements:

$f(r)=\sigma^{2} \times \exp ^{\left(-r^{2} / R^{2}\right)}$

where $R$ is the autocorrelation scale parameter and $\sigma$ is the variance and $r$ is the distance between data points. $R$ was determined from the fit of this covariance function to the raw covariances of the field observations. The method can make use of statistical results concerning measurement errors and small-scale noise inferred from the observed egg abundance data. Thus, at every single point an estimate can be given that depends linearly on the total number of measurements, i.e. a weighed sum of all observations. Based on repeated egg abundance observations at individual stations, it was obtained that the error due to measurement errors and small scale noise amounts to $15 \%$ of the total variance of the abundance fields and that these errors are normally distributed.

The surveys were designed to produce quasi-synoptic horizontal fields of sprat egg abundances, and a unit array configuration with a horizontal resolution of $5 \mathrm{~km}$ was chosen and superimposed on the standard station grid. For every year the same area of the applied standard station grid was used. Hereby, each of the grid points is representative of the analysed properties centred around it. However, only areas were considered where the expected root mean square of the interpolation was $<50 \%$ of the standard deviations of the observed egg abundance fields. Generally, the objective analysis method provides a smoothed version of the original measurements, with a tendency to underestimate the observed values because of the specific assumptions made regarding our treatment of measurement noise and small-scale signals unresolved by the meso-scale observation array. The error estimates depend only on the statistics of the field, the noise level, and on the locations of the observations, but not on the measurements themselves. In the worst case the objective analysis method underestimates the egg abundance by up to $30 \%$.

The number of surveys per year varied between 1 and 9. For all years, where a seasonal coverage was available, normal distribution curves were fitted to visualise the seasonal course of egg production in the investigated area (Fig. 3). It was assumed that the highest observed value is an indicator for the peak spawning and was therefore chosen for the DEPM calculation procedure (Table 1).

To obtain an estimation of the total daily egg production $\left(P_{0}\right)$, a temperature-dependent egg stage duration model is required. A model derived from experimental data (Haslob, 2011; Petereit et al., 2008) was applied:

$t d_{i}=5.58( \pm 0.54 S E) \times \exp ^{(-1 \times 0.012( \pm 0.008 S E) \times T)} \times E D S^{0.87( \pm 0.08)}$

where $t d_{i}$ is the endpoint of the $i$ th egg stage, $T$ is the ambient temperature $\left({ }^{\circ} \mathrm{C}\right)$, and $E D S$ is the specific egg developmental stage. It has been demonstrated that sprat eggs in the Bornholm Basin generally occur in water layers characterised by salinities of 8-12 psu
(Nissling et al., 2003). Therefore, the mean ambient temperature of these water layers during the respective ichthyoplankton survey was used for the estimation of egg stage durations. The observed mean egg abundance at stage could thus be converted into abundance at age. These were divided by the calculated stage duration of the respective stages to yield the egg production at time $t\left(P_{t}\right)$. Then, the daily egg production $\left(P_{0}\right)$ and daily mortality rates $(z)$ were estimated by fitting an exponential decay model to $P_{t}$ over age, i.e. the stage mid-points of distinct egg stages (Lo, 1985). All hydrographic data were derived from the ICES oceanographic data base (http://ocean.ices.dk).

\subsection{Stock structure, spawning fraction, and batch fecundity}

Sampling of adult sprat was carried out on several ichthyoplankton- and fishery surveys conducted in the Bornholm Basin during spawning time of sprat (Table 2). Length frequency distributions were calculated by measuring subsamples of at least 200 specimens to the nearest $\mathrm{cm}$ of each haul. Average length distributions were calculated by weighting the station specific length frequency distributions by the corresponding catch rates. Sex and maturity stages were determined by macroscopic inspection of at least 10 individuals per $1 \mathrm{~cm}$ length class from each haul. To estimate the spawning fraction $(S)$, the hydrated oocyte method was applied assuming that female sprat with hydrated oocytes will spawn within the next $12 \mathrm{~h}$ (Kraus and Köster, 2004) and thus hydrated oocytes can be used as daily spawning markers. However, although it is generally straightforward to identify hydrated oocytes by macroscopic inspection of fish ovaries (Hunter and Macewicz, 1985; DeMartini and Fountain, 1981), this method bears considerable uncertainties in the case of sprat due to the underlying assumption mentioned above, as the duration of the hydrated stage has never been directly estimated (Haslob et al., 2012). Further, the sampling may be biased since clupeid fish form female dominated spawning aggregations, and thus females with hydrated ovaries may be oversampled in some fishery hauls (Alheit, 1985).

To account for the aforementioned uncertainties in spawning fraction, different values were tested. In a first approach, the observed values per length class were utilised and contrasted to results based on the overall mean spawning fraction (24\%) to test for the impact of a possible length dependency of this parameter. Additionally, two scenarios of spawning fraction were used to investigate the potential impact of its uncertainty, i.e. half and double of the estimated mean value (12 and 48\%, respectively).

Fecundity $(F)$ was estimated by regression models taken from Haslob et al. (2011) with fish total length as predictor, and absolute batch fecundity as response variable (Table 2). For the year 2003 no fecundity data existed, therefore a model was used to estimate batch fecundity based on ambient temperature and fish size (Haslob et al., 2011).

\subsection{Estimation of stock size}

The stock size in numbers at sampling date $t\left(N_{t}\right)$ was estimated by applying a modified formula of the daily egg production method introduced by Kraus and Köster (2004) for Baltic sprat:

$N_{t}=\frac{P_{0}}{\sum_{8 \mathrm{~cm}}^{16 \mathrm{~cm}} L_{t, l} \times R_{t, l} \times M_{t, l} \times S_{t, l} \times F_{t, l}}$

where $P_{0}$ is the total daily egg production obtained from ichthyoplankton surveys in the field, $L_{t, l}$ is the relative frequency of length class $l$ at date $t, R_{t, l}$ is the sex ratio, $M_{t, l}$ is the proportion mature females, $S_{t, l}$ is the fraction of females spawning per day, and $F_{t, l}$ is the batch fecundity. 
Table 2

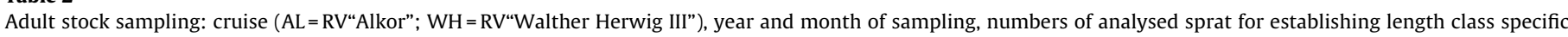

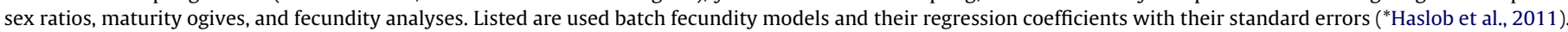
$F=$ batch fecundity, $L_{T}=$ total fish length.

\begin{tabular}{|c|c|c|c|c|c|c|c|c|}
\hline \multirow[t]{3}{*}{ Cruise } & \multirow[t]{3}{*}{ Month } & \multirow[t]{3}{*}{ Year } & \multicolumn{2}{|c|}{ Number of sprat analysed } & \multicolumn{4}{|c|}{ Batch fecundity models } \\
\hline & & & \multirow[t]{2}{*}{ Sex ratio, maturity } & \multirow[t]{2}{*}{ Fecundity } & \multicolumn{4}{|l|}{$F=y_{0}+L_{T} \times a$} \\
\hline & & & & & $y_{0}( \pm \mathrm{SE})$ & $a( \pm \mathrm{SE})$ & $r^{2}$ & $p$ \\
\hline AL143 & June & 1999 & 1738 & & $-2467( \pm 723)$ & $306( \pm 59)$ & 0.37 & $<0.05$ \\
\hline WH206 & June & 1999 & & 48 & & & & \\
\hline AL161 & May & 2000 & 831 & 51 & $-2971( \pm 1126)$ & $381( \pm 88)$ & 0.28 & $<0.05$ \\
\hline AL182 & May & 2001 & 1706 & & & & & \\
\hline WH228 & June & 2001 & & 62 & $-4076( \pm 1090)$ & $469( \pm 82)$ & 0.35 & $<0.05$ \\
\hline AL200 & April & 2002 & 1074 & & & & & \\
\hline WH239 & May & 2002 & & 61 & $-1583( \pm 793)$ & $246( \pm 63)$ & 0.21 & $<0.05$ \\
\hline AL217 & April & 2003 & 979 & & -2753 & 321 & From model* & \\
\hline WH263 & May & 2004 & & 67 & $-5561( \pm 1141)$ & $581( \pm 89)$ & 0.4 & $<0.05$ \\
\hline AL238 & June & 2004 & 564 & & & & & \\
\hline AL258 & May & 2005 & & & & & & \\
\hline WH275 & May & 2005 & 618 & 102 & $-2569( \pm 342)$ & $330( \pm 27)$ & 0.57 & $<0.05$ \\
\hline WH288 & May & 2006 & 1803 & 142 & $-2565( \pm 347)$ & $335( \pm 27)$ & 0.51 & $<0.05$ \\
\hline AL279 & June & 2006 & & & & & & \\
\hline AL297 & April & 2007 & & 14 & $-1843( \pm 1295)$ & $277( \pm 107)$ & 0.36 & $<0.05$ \\
\hline AL299 & May & 2007 & 617 & & & & & \\
\hline AL318 & April & 2008 & 3187 & 41 & $-4284( \pm 863)$ & $477( \pm 71)$ & 0.54 & $<0.05$ \\
\hline
\end{tabular}

Stock size estimations obtained from the DEPM for the Bornholm Basin sprat population were compared with stock size estimations from (i) an acoustic survey targeting sprat population in the central Baltic during peak spawning period (ICES, 2010b), and (ii) an area disaggregated multi species virtual population analysis (MSVPA; ICES, 2006). The abundance data from the acoustic survey are based on ICES rectangles. To obtain comparable stock abundance values, the abundance values were summed over the ICES rectangles covering only the Bornholm Basin for each year (ICES rectangles used: 38G5, 39G5, 40G5, 39G6, 40G6; Fig. 1; Table 3). The area disaggregated MSVPA stock abundance estimates are based on an ICES sub-division scale. Thus, they were down-scaled to the area of the Bornholm Basin by using distribution patterns obtained from the acoustic survey (Table 3; Köster, 1994).

To account for variability in the used stock parameters, confidence intervals for the obtained DEPM stock sizes were calculated using upper and lower confidence limits of each parameter in Eq. (3). For the stock parameters $L, R, M$, and $S, 95 \%$ confidence limits based on their standard deviations were calculated. In the case of batch fecundity, 95\% confidence limits based on the standard errors of regression coefficients (Table 2) were computed. In order to assess the impact of variability in mean ambient temperature on egg stage duration and thus $P_{0}$, the $95 \%$ confidence intervals of temperature in the range of 8-12 psu depth layers in which sprat eggs occur (Nissling et al., 2003) were calculated. These were applied to the daily egg production estimation to yield confidence intervals of $P_{0}$ (Table 4). To estimate the upper confidence limit of the stock size estimate, the upper confidence limit of $P_{0}$ and the lower one for the adult stock parameters $(L, R, M, S, F)$ was used, and vice versa for the lower stock size confidence limit. Finally, the uncertainty of the integrated egg abundance estimate in the study area by the objective analysis was added as a fixed value (30\% maximum possible underestimation) on top of these confidence limits to display the maximum possible uncertainty in DEPM stock size estimates (Figs. 6 and 7).

\section{Results}

\subsection{Egg abundance, egg mortality, and daily egg production}

Egg abundance as well as egg distribution patterns showed distinct variability over the observed time period. At peak spawning, sprat eggs occurred on nearly all stations of the survey grid. The margins of the basin showed in general lower egg abundances compared to the centre (Fig. 2). However, in some years with high egg abundances (e.g. 1999), high values were also found at the margins, indicating that not the entire spawning area was covered by the survey. Maximum egg abundance ranged from $5.62 \times 10^{12}$ eggs in June 1999 to $1.14 \times 10^{12}$ eggs in May 2005 (Fig. 3; Table 1). Peak values of egg abundances were mostly observed between May and June. In 2003 maximum egg abundance was observed in March, in 2002 and 2008 the maximum egg stage I abundance was observed in April. No egg abundance curves could be fitted in 2000 and 2001, due to limited data. Therefore, it is not

Table 3

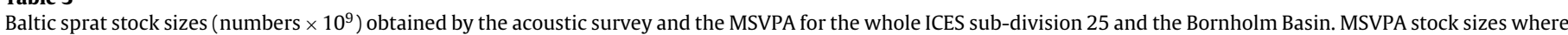
down-scaled with the share of the stock in the Bornholm Basin obtained by the acoustic survey.

\begin{tabular}{|c|c|c|c|c|c|}
\hline \multirow[t]{2}{*}{ Year } & \multicolumn{3}{|c|}{ Quarter 2 acoustic survey } & \multicolumn{2}{|l|}{ MSVPA } \\
\hline & $\begin{array}{l}\text { ICES SD25 } \\
\left(n \times 10^{9}\right)\end{array}$ & $\begin{array}{l}\text { Bornholm Basin } \\
\left(n \times 10^{9}\right)\end{array}$ & $\begin{array}{l}\text { Share of stock in the Bornholm Basin } \\
(\%)\end{array}$ & $\begin{array}{l}\text { ICES SD25 } \\
\left(n \times 10^{9}\right)\end{array}$ & $\begin{array}{l}\text { Bornholm Basin } \\
\left(n \times 10^{9}\right)\end{array}$ \\
\hline 1999 & 40.81 & 16.63 & 40.76 & 52.76 & 21.51 \\
\hline 2000 & n.a. & n.a. & n.a. & 44.22 & 22.68 \\
\hline 2001 & 29.58 & 9.21 & 31.14 & 32.50 & 10.12 \\
\hline 2002 & 52.91 & 35.59 & 67.26 & 29.40 & 19.77 \\
\hline 2003 & 11.40 & 6.47 & 56.74 & 28.01 & 15.90 \\
\hline 2004 & 28.02 & 14.55 & 51.92 & 43.96 & 22.83 \\
\hline 2005 & 35.79 & 23.45 & 65.51 & 34.05 & 22.31 \\
\hline 2006 & 21.00 & 11.50 & 54.77 & n.a. & n.a. \\
\hline 2007 & 22.46 & 11.88 & 52.88 & n.a. & n.a. \\
\hline 2008 & 22.74 & 10.65 & 46.83 & n.a. & n.a. \\
\hline
\end{tabular}


Table 4

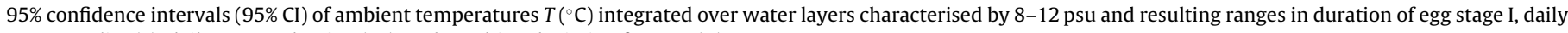
egg mortality $(z)$, daily egg production $\left(P_{0}\right)$, and resulting deviation from $P_{0}(\%)$.

\begin{tabular}{|c|c|c|c|c|c|c|}
\hline \multirow[t]{2}{*}{ Year } & \multirow[t]{2}{*}{$95 \%$ CI T } & \multirow[t]{2}{*}{ Duration egg stage I } & \multirow[t]{2}{*}{$z$} & \multirow[t]{2}{*}{$P_{0} \times 10^{12}$} & \multicolumn{2}{|c|}{ Deviation from $P_{0}$} \\
\hline & & & & & $T(\mathrm{CI}-95 \%)$ & $T(\mathrm{CI}+95 \%)$ \\
\hline 1999 & $3.85-6.23$ & $2.72-3.58$ & $0.38-0.50$ & $3.11-4.09$ & -13 & 15 \\
\hline 2000 & $4.17-4.96$ & $3.15-3.45$ & $0.14-0.15$ & $0.60-0.66$ & -4 & 5 \\
\hline 2001 & $3.97-4.75$ & $3.23-3.53$ & $0.19-0.21$ & $1.51-1.66$ & -4 & 5 \\
\hline 2002 & $4.48-5.97$ & $2.80-3.33$ & $0.80-0.94$ & $3.10-3.68$ & -8 & 9 \\
\hline 2003 & $2.44-4.50$ & $3.32-4.21$ & $0.51-0.65$ & $1.31-1.66$ & -11 & 13 \\
\hline 2004 & $4.03-5.09$ & $3.10-3.51$ & $0.23-0.26$ & $0.67-0.75$ & -6 & 6 \\
\hline 2005 & $3.64-4.73$ & $3.23-3.67$ & $0.20-0.22$ & $0.45-0.51$ & -6 & 6 \\
\hline 2006 & $2.80-3.50$ & $3.72-4.04$ & $0.26-0.29$ & $1.10-1.20$ & -4 & 4 \\
\hline 2007 & $4.73-5.34$ & $3.01-3.23$ & $0.18-0.19$ & $1.85-1.98$ & -3 & 4 \\
\hline 2008 & $4.53-7.16$ & $2.45-3.31$ & $0.18-0.25$ & $1.63-2.21$ & -8 & 25 \\
\hline
\end{tabular}

fully assured that the abundance estimate reflects the situation during peak spawning in these years, since egg abundance may almost triple within two weeks, like observed in May/June 1999 (Fig. 3).
Estimation of daily egg mortality resulted in mortality coefficients ranging from 0.14 to 0.87 . Highest daily egg production was observed for June 1999, the lowest value was found in May 2000 (Table 1). The fitted mortality models were significant in most cases
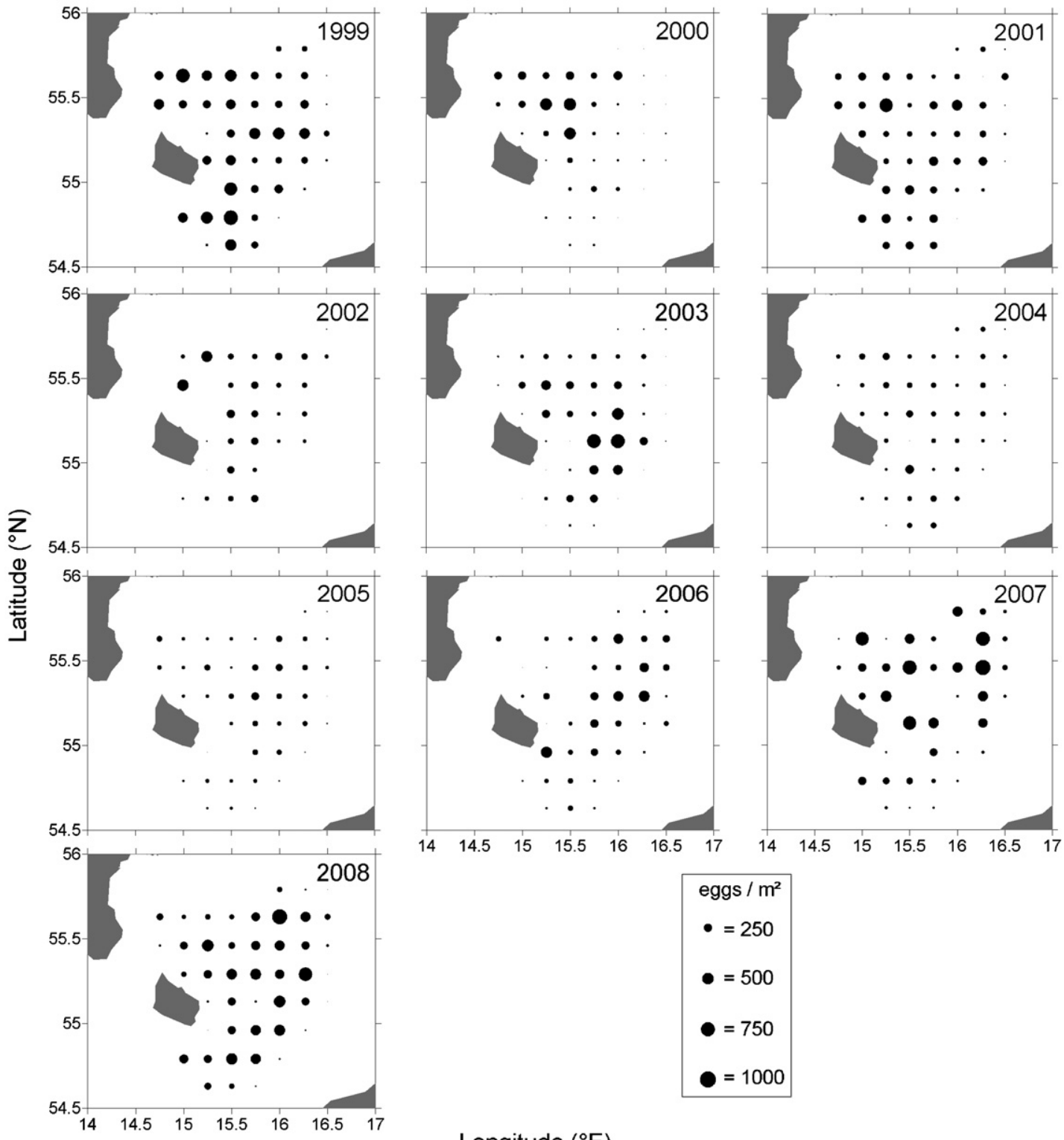

$$
\begin{aligned}
& \text { eggs } / \mathrm{m}^{2} \\
& \bullet=250 \\
& =500 \\
& =750 \\
& =1000
\end{aligned}
$$

Longitude $\left({ }^{\circ} \mathrm{E}\right)$

Fig. 2. Spatial distribution of sprat eggs in the Bornholm Basin during peak spawning time 1999-2008.

Please cite this article in press as: Haslob, H., et al., Application of the daily egg production method to Baltic sprat. Fish. Res. (2012), http://dx.doi.org/10.1016/j.fishres.2012.03.008 

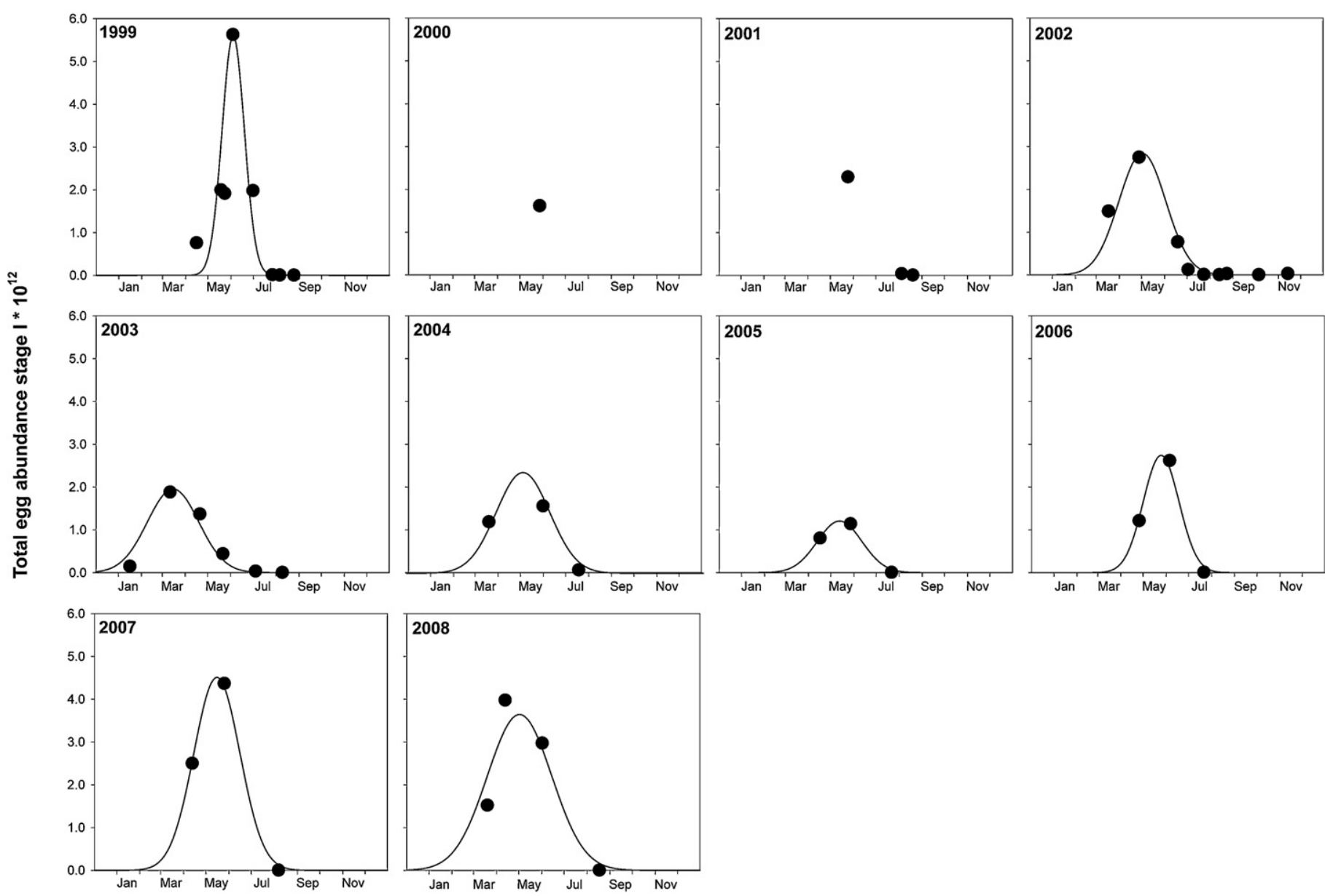

\section{Date}

Fig. 3. Total seasonal egg stage I abundance in the Bornholm Basin for the years 1999-2008.

(Fig. 4; Table 1). However, in some cases parameter estimates of the exponential decay model were not significant.

\subsection{Adult stock parameters}

In all years the majority of fish ranged from $>11 \mathrm{~cm}$ to $<13 \mathrm{~cm}$ (Fig. 5). In 2002, 2003, and 2004, a bimodal distribution was observed caused by a high proportion of smaller individuals. In 2004 , the relative length frequency was more evenly distributed in comparison to all other years.

Proportion of females increased with fish size for all observed years (Fig. 5). Variability was highest in the smaller length classes, probably due to low sample sizes and uncertainties in macroscopic identification of sexes in immature, small fish $<10 \mathrm{~cm}$.

Proportion of mature females showed a sharp increase with size in some years (e.g. 2000, 2001), changing from around $20 \%$ up to $100 \%$ from one cm-length class to the next. In general the L50\% values ranged between $9.5 \mathrm{~cm}$ and $10.5 \mathrm{~cm}$ length. In most cases female sprat $>12.5 \mathrm{~cm}$ were all mature.

Daily spawning fraction of the female stock, obtained by the hydrated oocyte method, ranged in most cases between 20 and $30 \%$ (Fig. 5). The overall mean spawning fraction was $24 \%$. However, considerably higher values for single size classes were observed in some cases, e.g. in the year 2004 up to $50 \%$ in length class $12-13 \mathrm{~cm}$. Further, in 2003 a low proportion of females with hydrated oocytes was detected which resulted in very low spawning fractions. No clear trend of spawning fraction with fish size was detected. In some years an increase with length could be shown, whilst in other years even a decrease with fish length was observed. In most years no spawning fraction could be estimated for fish $<9.5 \mathrm{~cm}$, although some of these females were classified as mature, but no hydrated females were found in the samples.

\subsection{Stock size}

Considering the $95 \%$ confidence intervals around the adult stock parameters leads to an uncertainty in DEPM based stock size estimates in the range of $-27 \%$ (Fig. 6a year 2007) to $+47 \%$ (Fig. 6a year 2005), when variability in spawning fraction is taken into account. The largest deviation in absolute numbers occurs in those years where the stock size estimate is highest (Fig. 6 e.g. 2003). The confidence interval becomes narrower when spawning fraction is set constant (Figs. 6b and 7). These confidence limits and that caused by deviations in $P_{0}$ due to variability in ambient temperature (min $-13 \%$, max. 25\%; Table 4) were used to recalculate the DEPM estimates to create upper and lower confidence limits (Figs. 6 and 7).

The two approaches using either observed spawning fraction values per length class or the observed mean value resulted in similar trends in the estimated DEPM stock sizes with high interannual variability (Fig. 6). Stock sizes obtained by the DEPM were highest in the year 1999, followed by the lowest stock size in 2000 . For the years 2002 and 2003 also high stock sizes were obtained, but for 2003 only when using the length class specific observed spawning fractions; the high stock size in 2003 is thus due to an exceptional low observed spawning fraction in this year. The DEPM then provided comparatively low stock size estimates for the years 2004 and 


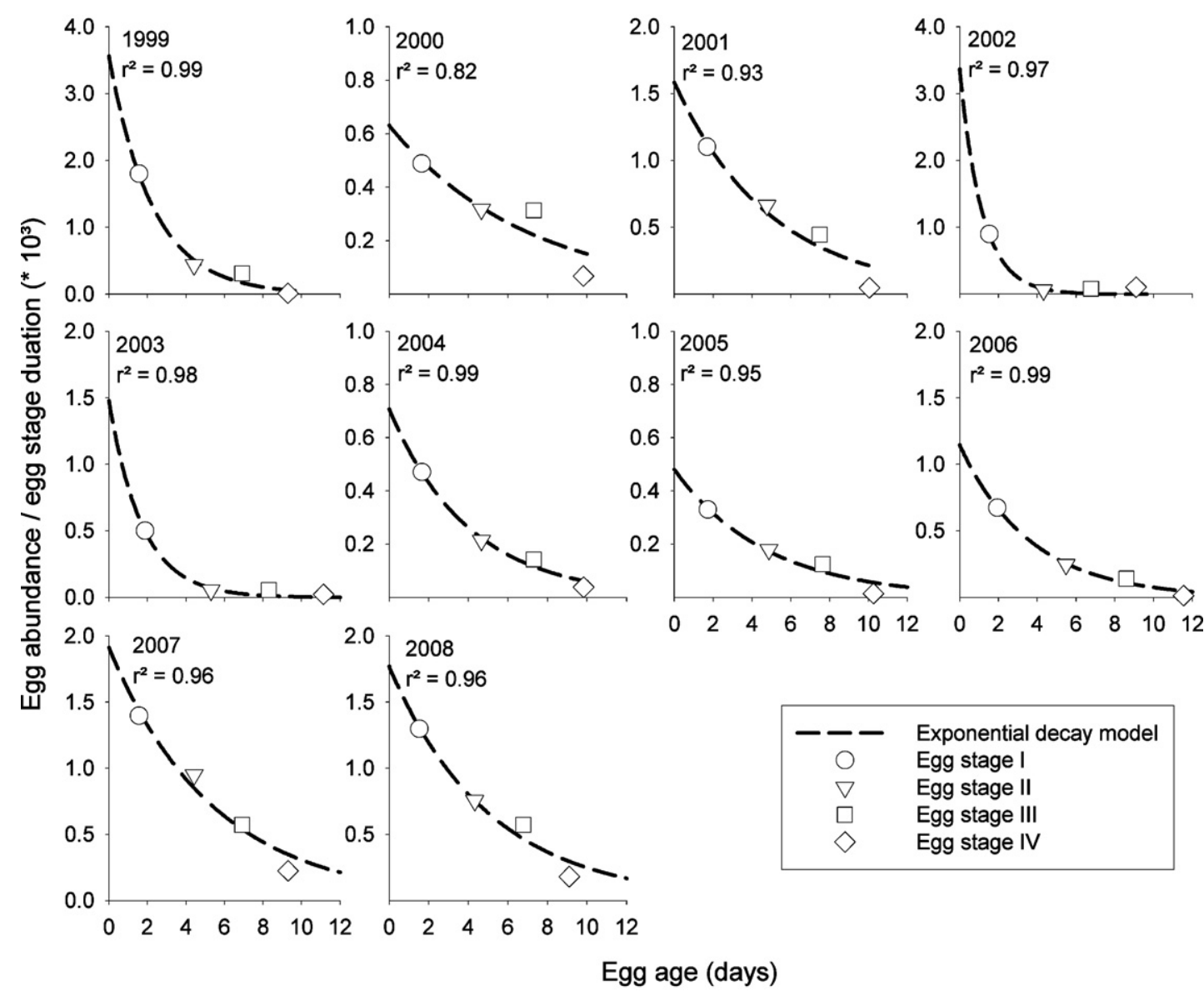

Fig. 4. Exponential decay models fitted through egg abundance at age data, yielding daily mortality rate $(z)$ and daily egg production $\left(P_{0}\right)$.

2005. A continuous increase in stock size for the last three years of the time series was observed.

In the acoustic survey stock estimates, variability amongst years was higher. Similar to the DEPM, the acoustic survey detected a peak in sprat abundance in 2002, although the acoustic estimate is higher in this year compared to the DEPM estimates. The acoustic stock estimates for the years 2004 and 2005 showed considerable higher values compared to the DEPM with an opposite trend for these two years. In 1999, the acoustic stock size was considerably lower than the DEPM estimate. This was also the case for 2003, but only when using the observed length class specific spawning fractions. The acoustic survey revealed that between $31 \%$ and $67 \%$ of the total sprat stock in ICES sub-division 25 were detected within the Bornholm Basin during the survey. Accordingly, the highest absolute stock sizes in the Bornholm Basin were observed in those years where proportions of fish acoustically detected within the basin were also high.

The MSVPA stock estimates (Table 3) were generally less variable amongst years compared to the other two methods. Only for two years (2001 and 2002), it was in good agreement with the DEPM estimates (Fig. 6a and b). For most years, the MSVPA stock size was higher compared to the DEPM, apart from the years 1999 and 2002. Compared to the acoustic estimate, the MSVPA was also higher for most of the years, but was in good accordance for the years 2001 and 2005. Generally the trend of the MSVPA values was similar to that of the acoustic survey, which is due to the use of acoustic distribution patterns to down-scale MSVPA results (Table 4).

The DEPM results obtained by the two different spawning fraction scenarios were markedly different from the acoustic and MSVPA stock estimates (Fig. 7). In scenario I ( $S=12 \%$ ) the DEPM stock sizes doubled and were now higher in a number of years compared to the acoustic, and in some years compared to the MSVPA estimates, even exceeding both methods more than threefold in 1999. The DEPM and the acoustic stock estimate were in good accordance in 2004 and 2006. In scenario II $(S=48 \%)$ the DEPM estimates, and even the upper limit of its confidence intervals, are lower compared to all other estimates, apart from the years 1999 and 2003 where it nearly equals the acoustic estimates.

\section{Discussion}

The application of the daily egg production method to Baltic sprat spawning in the Bornholm Basin is a challenging exercise. The Baltic sprat stock exhibits some peculiarities compared to other clupeid species for which this method has been applied previously. The Bornholm Basin is a brackish water habitat with a unique stratified hydrography, where egg survival is confined to specific water layers with favourable temperature, salinity and oxygen conditions and thus strongly dependent on egg buoyancy. The vertical distribution of sprat eggs was assumed to be confined to water layers characterised by 8-12 psu based on experiments made by Nissling et al. (2003). A novelty of the present study is the application of a temperature sensitive egg stage duration model based on ambient temperatures of buoyant eggs and the corresponding effect on egg mortality rates and $P_{0}$. The results of the present study demonstrated that the stock size estimates might already change up to $25 \%$ due to the range in ambient mean temperatures observed within the 8-12 psu layer. Thus, ignoring the effect of ambient temperatures on egg survival will strongly bias the DEPM estimates. In a previous application of the DEPM to 

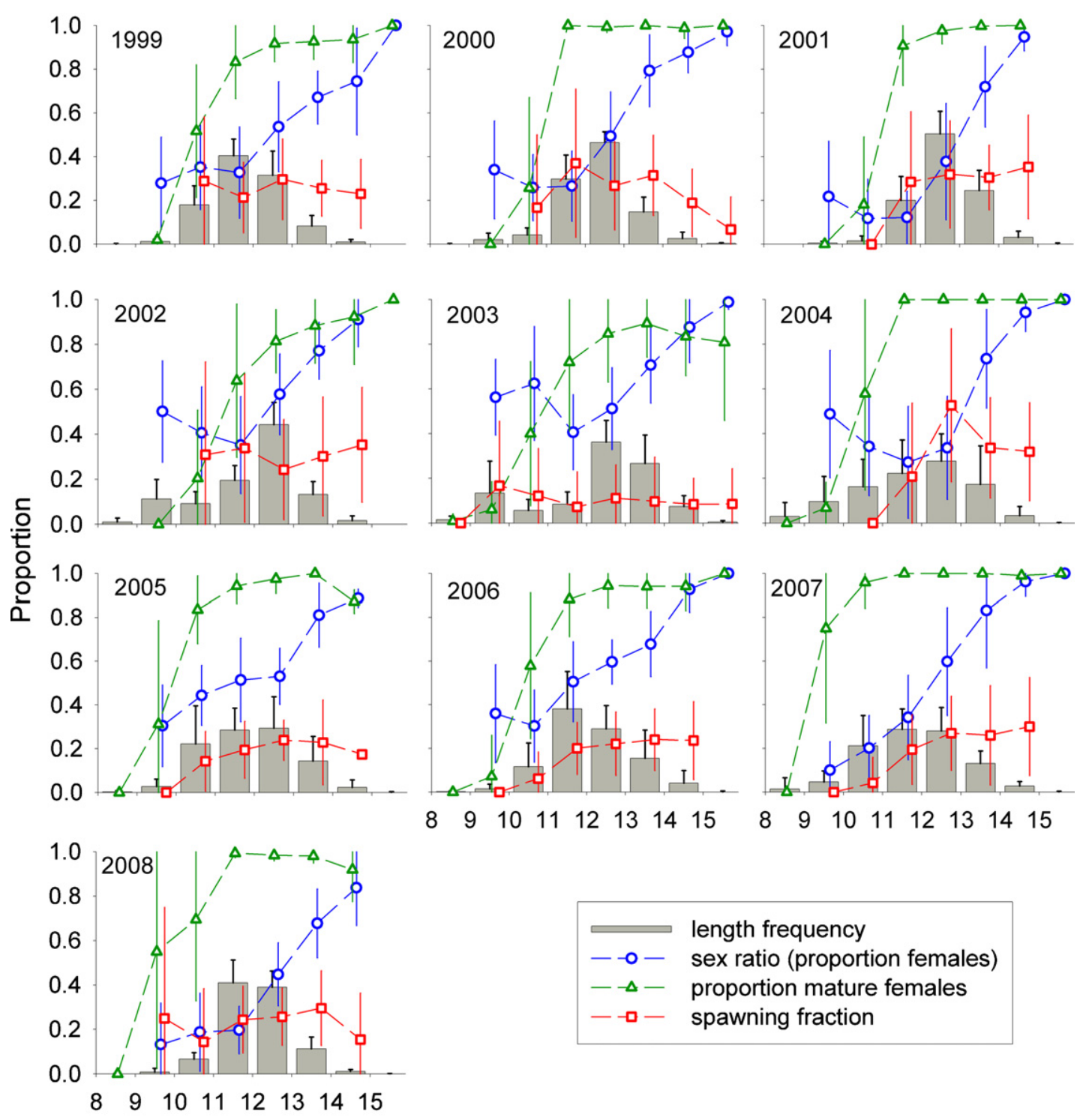

\section{Length class $(\mathrm{cm})$}

Fig. 5. Adult stock parameters $( \pm S D$ ) of sprat observed during peak spawning time for the years 1999-2008.

sprat in this area (Kraus and Köster, 2004), the duration of the youngest egg stage I was assumed to last one day, and thus its abundance equalled the daily egg production, neglecting both mortality within this stage and temperature-dependent changes in egg stage duration.

In contrast to other clupeid species, sprat in the Baltic Sea do not show a well synchronised diel spawning pattern (Alekseev and Alekseeva, 2005; Haslob et al., 2012) and consequently large uncertainties reside in the estimates of the daily spawning fraction (Hunter and Macewicz, 1985). The daily spawning fraction is also generally one of the parameters with the highest uncertainty in DEPM applications (Stratoudakis et al., 2006) with considerable consequences for the estimation of the spawning stock size. Usually, daily spawning fraction is determined by the postovulatory follicle (POF) method or by the hydrated oocyte method (Hunter and Macewicz, 1985). To be consistent with previous studies on Baltic sprat (Kraus and Köster, 2004; Alekseev and Alekseeva, 2005) and to enable inclusion of historic data in the time series of DEPM based stock sizes, the hydrated oocyte method was chosen for the present study.
Regardless which method is used to estimate daily spawning fraction, the duration of either the POF stages or the hydrated stage has to be known. This can be achieved by tank experiments or by field observations, given that the diel spawning pattern is wellsynchronised. Since this seems not to be the case in Baltic sprat (Alekseev and Alekseeva, 2005; Haslob et al., 2012), tank experiments would be most desirable to determine exact POF or hydrated oocyte durations and to increase the precision of the estimates (Ganias, 2012). However, such laboratory experiments are lacking so far, because it was not feasible to keep mature sprat in tanks for this purpose. Hence, all available information on daily spawning fraction of Baltic sprat is based on the hydrated oocyte method (Kraus and Köster, 2004; Alekseev and Alekseeva, 2005), assuming a duration of the hydrated stage of less than $24 \mathrm{~h}$ based upon observations in other clupeid species (Hunter and Macewicz, 1985). Furthermore, this method may be biased through oversampling of spawning females, as they tend to form schools distinct from the rest of the population (Alheit, 1985). However, the fishing gear in use was designed to cover the entire water column where sprat shoals concentrate. 

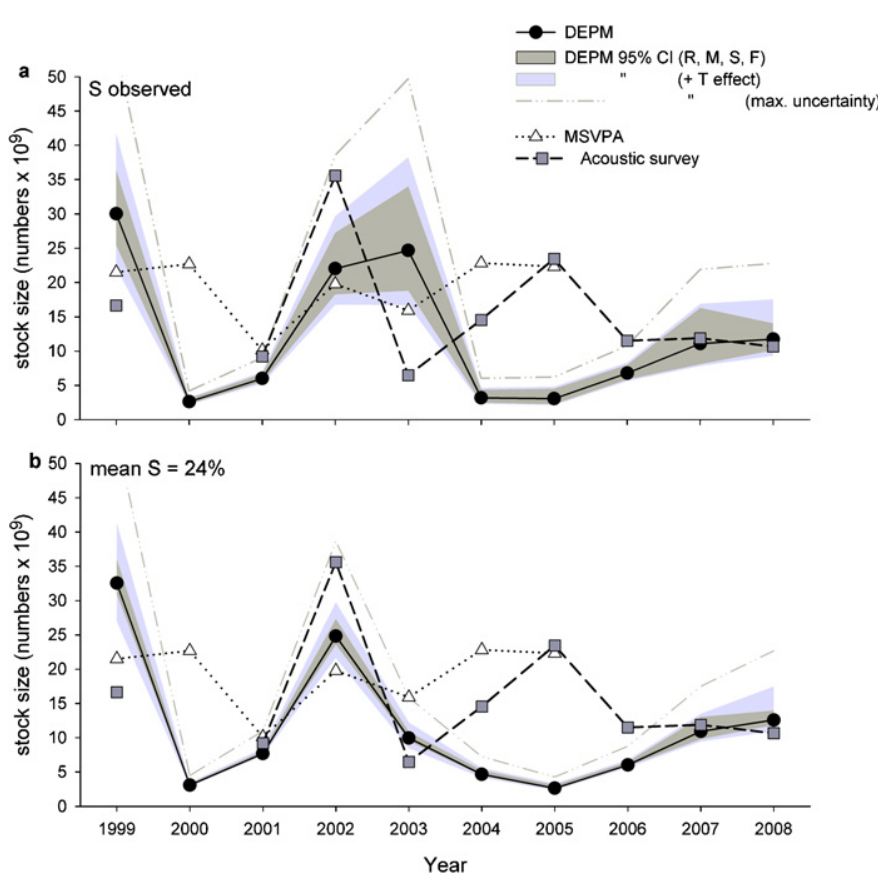

Fig. 6. Stock abundance data obtained from the acoustic survey (grey squares, dashed line), the MSVPA (white triangles, dotted line), and the DEPM (black circles, solid line). DEPM stock sizes estimated with (a) length class specific observed spawning fractions, and (b) mean spawning fraction. Confidence intervals account for variability in stock parameters, temperature effect on daily egg production, and uncertainty in egg abundance estimate.

For the present study, having for the first time large enough sample sizes of spawning sprat allowed us to produce length and date specific values of spawning fraction. Thus, the potential source of error related to undersampling was minimised compared to other studies on Baltic sprat where spawning fraction had to be averaged
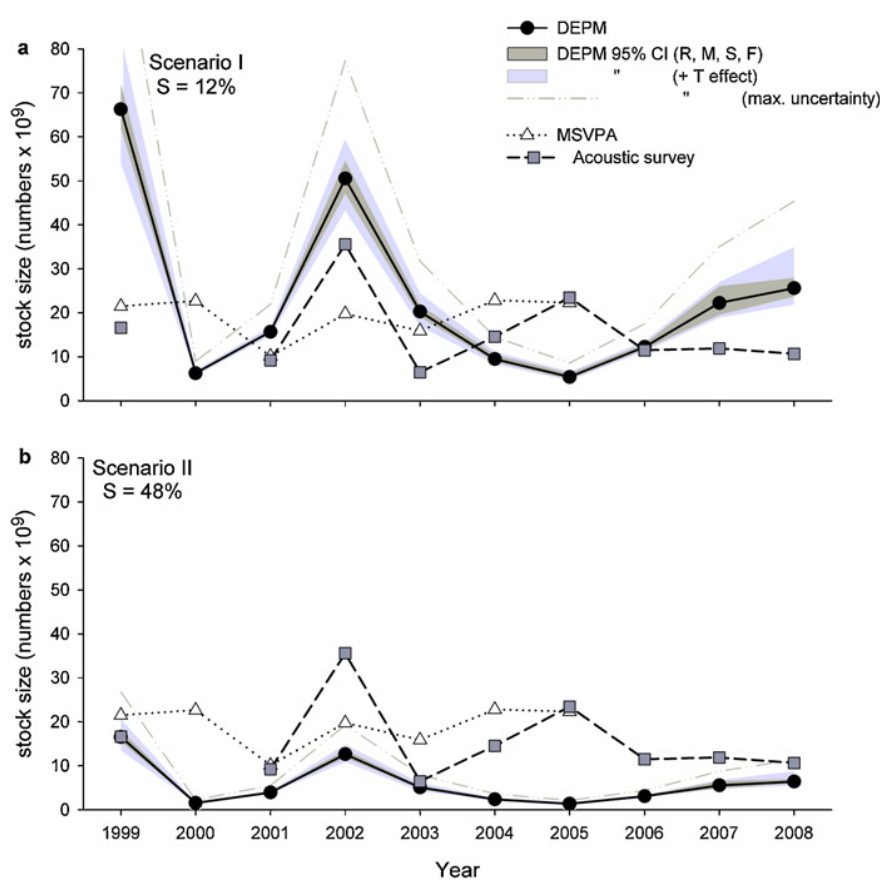

Fig. 7. Stock abundance data obtained from the DEPM (black circles, solid line), the acoustic survey (grey squares, dashed line), and the MSVPA (white triangles, dotted line) compared to (a) DEPM scenario I $S=12 \%$, (b) DEPM scenario II $S=48 \%$. Confidence intervals account for variability in stock parameters, temperature effect on daily egg production, and uncertainty in egg abundance estimate. over years and size classes (e.g. Kraus and Köster, 2004). Results of the present study confirm literature values of the proportion of hydrated females in the range of $22-25 \%$ for sprat and provide additional evidence that a spawning interval of 4.5-4 days (i.e. $S=$ proportion hydrated) might be realistic for Baltic sprat. This was justified by the use of these values in the present DEPM application which resulted in a rather good accordance between stock sizes obtained by the acoustic survey and the DEPM, two totally independent assessment methods.

Similar to our results, spawning intervals in the range of approximately four days were described for other clupeid fish, e.g. sardine (Sardina pilchardus) off Spain (East Cantabria) with a daily spawning fraction ranging between $21 \%$ and $23 \%$ (see review in Ganias et al., 2003). Somewhat higher values were reported for Bay of Biscay anchovy (Engraulis encrasicolus), ranging between 26\% and $32 \%$ (Motos, 1996), which is also in the range of the observed values for Baltic sprat. Spawning fractions in the range used for scenario II or even higher have only been reported for tropical species (e.g. Sardinella brasiliensis, Isaac-Nahum et al., 1988; Encrasicolina purpurea, Clarke, 1987). As temperatures in the Baltic are normally lower during sprat peak spawning compared to the aforementioned examples, we assume that the true spawning fraction of Baltic sprat is similar to or slightly lower than the observed for other North Atlantic clupeids. Nevertheless, it is highly recommended that the daily spawning fraction of Baltic sprat is further assessed, and former estimations re-evaluated, e.g. applying gonadal histology. This would also be valuable information for a number of other applications for which the seasonal egg production and total reproductive investment is addressed, e.g. life stage based population models or bioenergetic models.

Claramunt et al. (2007) reported that the spawning fraction of Sardinops sagax and Engraulis ringens is positively related to fish size. Our data indicate that this might also be true for Baltic sprat. However, the much lower proportion mature and the lower fecundity in the smaller length classes dampen the effect on the estimated total stock size. Because spawning fractions were relatively stable within the larger length classes that most contribute to egg production, we did not find pronounced differences between DEPM stock size estimates using either length class specific spawning fractions or an overall mean (Fig. 6).

Likewise, high variability was observed in sex ratios and proportion mature fish. Especially for the smallest length classes, mean values might be uncertain. This can be explained by (i) uncertainties of sex and maturity classification in these small fish by macroscopic inspection of ovaries and (ii) inadequately small sample sizes of the smallest length classes in some cases. In contrast, determination of relative length frequency distribution is straightforward and sample sizes were in all cases sufficient to get a representative estimation. In summary, the error introduced by these other input parameters was generally lower than observed for spawning fraction and thus does not result in a comparable impact on DEPM estimates.

We assumed that all oocytes were spawned and have been fertilised successfully. However, fertilisation rates may be dependent on hydrographic parameters, e.g. temperature or salinity. Therefore, it is likely that a proportion of oocytes might not be fertilised under certain circumstances (Markle and Waiwood, 1985; Hempel, 1979). Unfertilised eggs rapidly sink down to the bottom and were thus underestimated in our egg production estimates. To further enhance the accuracy of the DEPM, fertilisation success in relation to hydrography should be included in future studies.

Quantitative studies on recruitment processes of sprat and cod, for example the estimation of predation pressure on cod and sprat early life stages by sprat (Köster and Möllmann, 2000a,b; Voss et al., 2011) were so far hampered by conflicting results on Baltic sprat stock size estimates from acoustic surveys and MSVPA. The DEPM 
stock estimates were in the same order of magnitude as the results from acoustic survey and the area disaggregated MSVPA, adding evidence to its applicability as fishery data independent method to estimate stock sizes and as valuable tool to gain better confidence in conflicting stock estimates.

In the present study, we presented a 10-year time series of sprat spawning stock size obtained from sources independent of commercial catch data. Although we could identify a number of methodological shortcomings especially in relation to spawning fraction (see above), the order of magnitude of our estimates was comparable to MSVPA results downscaled to this spawning component and spawning stock numbers estimated by hydroacoustics. Trends and peaks in specific years were somewhat different, indicating a greater sensitivity of the DEPM compared to especially the MSVPA, which is known to smooth stock trends of cod compared to egg production methods (Kraus et al., 2012).

In conclusion, the present study revealed the applicability of the DEPM to assess stock components of the Baltic sprat stock. Improvements have to be made in future applications to minimise the remaining uncertainties, in particular regarding diel spawning pattern. If these uncertainties can be ruled out, the DEPM is the most promising and cost effective alternative retrospective fishery independent assessment method to assess the Baltic sprat stock size.

\section{Acknowledgements}

We would like to thank all those involved in the sampling of sprat during all of the cruises. Thanks to the crews of RV "Alkor" and RV "Walther Herwig III". Thanks to Prof. D. Schnack for valuable comments on an earlier version of the manuscript. We acknowledge two anonymous reviewers for valuable comments and criticisms. This research was supported by the COST action FRESH (FA0601) "Fish Reproduction and Fisheries" and by the German Science Foundation (DFG) cluster project RECONN2 \#CL126/3-1 (Resolving Trophodynamic Consequences of Climate Change) within the priority program 1162 AQUASHIFT.

\section{References}

Alekseev, F.E., Alekseeva, E.I., 2005. Batch fecundity and daily egg production of the Baltic sprat Sprattus sprattus balticus (Clupeidae) from the southeastern part of the Baltic Sea. J. Ichthyol. 45 (1), 93-102.

Alheit, J., 1985. Spawning frequency of Peruvian anchovies taken with a purse seine. In: Lasker, R. (Ed.), An Egg Production Method for Estimating Spawning Biomass of Pelagic Fish: Application to the Northern Anchovy, Engraulis mordax. NOAA Technical Report, NMFS 36. , pp. 59-62.

Alheit, J., 1993. Use of the daily egg production method for estimating biomass of clupeoid fishes: a review and evaluation. Bull. Mar. Sci. 53 (2), 750-767.

Bretherton, F.P., Davis, R.E., Fandry, C.B., 1976. A technique for objective analysis and design of oceanographic experiments applied to MODE-73. Deep Sea Res. $23,559-582$.

Claramunt, G., Serra, R., Castro, L.R., Cubillos, L., 2007. Is the spawning frequency dependent on female size? Empirical evidence in Sardinops sagax and Engraulis ringens off northern. Chile Fish. Res. 85, 248-257.

Clarke, T.A., 1987. Fecundity and spawning frequency of the Hawaiian anchovy or nehu, Encrasicolina purpurea. Fish. Bull. NOAA 85, 127-138.

DeMartini, E.E., Fountain, R.K., 1981. Ovarian cycling frequency and batch fecundity in the queenfish, Seriphus politus: attributes representative of serial spawning fishes. Fish. Bull. NOAA 79, 547-560.

Ganias, K., 2012. Thirty years of using the postovulatory follicles method: overview, problems and alternatives. Fish. Res. 117-118, 63-74.

Ganias, K., Somarakis, S., Machias, A., Theodorou, A.J., 2003. Evaluation of spawning frequency in a Mediterranean sardine population (Sardina pilchardus sardina). Mar. Biol. 142, 1169-1179.

Grauman, G.B., Krenkel, K., 1986. Dynamik des Laichens des Ostseesprotts. FischereiForschung Rostock 24, 38-42 (in Russian, abstract in German).

Grygiel, W., Wyszyński, M., 2003. Temporal (1980-2001) and geographic variation in the sexual maturity at age and length of herring and sprat inhabiting the southern Baltic. Bull. Sea Fish. Inst. 2 (159), 3-34.
Haslob, H., 2011. Reproductive ecology of Baltic sprat and its application in stock assessment. Dissertation. Christian-Albrechts-University, Kiel, Germany, 133 pp.

Haslob, H., Tomkiewicz, J., Hinrichsen, H.H., Kraus, G., 2011. Spatial and interannual variability in Baltic sprat batch fecundity. Fish. Res. 110 (2), 289-297.

Haslob, H., Kraus, G., Saborido-Rey, F., 2012. The dynamics of postovulatory follicle degeneration and oocyte growth in Baltic sprat. J. Sea Res. 67, 27-33.

Hempel, G., 1979. Early Life History of Marine Fish: The Egg Stage. University of Washington Press, Seattle, USA, 70 pp.

Hensen, V., Apstein, C., 1897. Die Nordsee Expedition 1895 des Deutschen Seefischerei Vereins: Über die Eimenge der im Winter laichenden Fische. Wissenschaftliche Meeresuntersuchung. Bd. 2 (2), 1-97.

Hunter, J.R., Macewicz, B.J., 1985. Measurement of spawning frequency in multiple spawning fishes. In: Lasker, R. (Ed.), An Egg Production Method for Estimating Spawning Biomass of Pelagic Fish: Application to the Northern Anchovy, Engraulis mordax. NOAA Technical Report, NMFS 36. pp. 79-94.

ICES, 2006. Report of the Study Group on Multispecies Assessment in the Baltic (SGMAB). ICES CM 2006/BCC:07.

ICES, 2010a. Report of the Baltic Fisheries Assessment Working Group (WGBFAS) ICES CM 2010/ACOM:10.

ICES, 2010b. Manual for the Baltic International Acoustic Survey (BIAS). Addendum 2: WGBIFS BIAS Manual Version 0.82.

Isaac-Nahum, V.J., de Cardoso, R., Servo, G., Rossi-Wongtschotski, 1988. Aspects of the spawning biology of the Brasilian sardine, Sardinella brasiliensis (Steindacher 1879) (Clupeidae). J. Fish Biol. 32, 383-396.

Köster, F.W., 1994. Der Einfluß von Bruträubern auf die Sterblichkeit früher Jugendstadien des Dorsches (Gadus morhua) und der Sprotte (Sprattus sprattus) in der zentralen Ostsee, vol. 261. Berichte aus dem Institut für Meereskunde an de Christian Albrechts-Universität, Kiel, 286 pp. (in German).

Köster, F.W., Möllmann, C., 2000a. Trophodynamic control by clupeid predators on recruitment success in Baltic cod? ICES J. Mar. Sci. 57, 310-323.

Köster, F.W., Möllmann, C., 2000b. Egg cannibalism in Baltic sprat Sprattus sprattus. Mar. Ecol. Prog. Ser. 196, 269-277.

Köster, F.W., Schnack, D., 1994. The role of predation on early life stages of cod in the Baltic. Dana J. Fish. Mar. Res. 10, 179-201.

Kraus, G., Köster, F.W., 2004. Estimating Baltic sprat (Sprattus sprattus balticus S.) population sizes from egg production. Fish. Res. 69, 313-329.

Kraus, G., Hinrichsen, H.H., Voss, R., Teschner, E., Tomkiewicz, J., Köster, F.W., 2012. Robustness of egg production methods as a fishery independent alternative to assess the Eastern Baltic cod stock (Gadus morhua callarias L.). Fish. Res. 117-118, 75-85.

Lasker, R., 1985. An Egg Production Method for Estimating Spawning Biomass of Pelagic Fish: Application to the Northern Anchovy, Engraulis mordax. NOAA Technical Report, NMFS 36, 99 pp.

Lo, N.C.H., 1985. A model for temperature-dependent anchovy egg development and an automated procedure for the assignment of age to staged eggs. In: Lasker, $\mathrm{R}$. (Ed.), An Egg Production Method for Estimating Spawning Biomass of Pelagic Fish: Application to the Northern Anchovy, Engraulis mordax. NOAA Technical Report, NMFS 36. , pp. 43-50.

Macarchouk, A, 2007. The Assessment of the Spawning-stock Biomass of Sprat in the Gotland Basin (Eastern Baltic Sea) with the Hensen-Apstein Method with some Innovations, ICES CM 2007/0:12.

Macarchouk, A., Yula, E., 2001. Calculation of the Spawning-Stock Biomass of Sprat in the Gotland Basin (Eastern Baltic Sea) with the Hensen-Apstein Method, ICES CM 2001/J:31.

Markle, D.F., Waiwood, G.W., 1985. Fertilization failure in gadids: aspects of its measurement. J. Northwest Atl. Fish. Sci. 6, 87-93.

Motos, L., 1996. Reproductive biology and fecundity of the Bay of Biscay anchovy population (Engraulis encrasicolus L.). Sci. Mar. 60 (Suppl. 2), 195-207.

Nissling, A., Müller, A., Hinrichsen, H.H., 2003. Specific gravity and vertical distribution of sprat eggs in the Baltic Sea. J. Fish Biol. (63), 280-299.

Parker, K., 1980. A direct method for estimating northern anchovy, Engraulis mordax, spawning biomass. Fish. Bull. NOAA 78, 541-544.

Petereit, C., Haslob, H., Kraus, G., Clemmesen, C., 2008. The influence of temperature on the development of Baltic Sea sprat (Sprattus sprattus) eggs and yolk sac larvae. Mar. Biol. 154, 295-306.

Somarakis, S., Palomera, I., Garcia, A., Quintanilla, L., Koutsikopoulos, C., Uriarte, A. Mostos, L., 2004. Daily egg production of anchovy in European waters. ICES J. Mar. Sci. 61, 944-958.

Stratoudakis, Y., Bernal, M., Ganias, K., Uriarte, A., 2006. The daily egg production method: recent advances, current applications and future challenges. Fish Fish. 7, 35-57.

Thompson, B.M., Milligan, S.P., Nichols, J.H., 1981. The Development Rates of Sprat (Sprattus sprattus L.) Eggs over a Range of Temperatures, ICES CM 1981/H15.

Voss, R., Hinrichsen, H.H., Stepputtis, D., Bernreuther, M., Huwer, B., Neumann, V. Schmidt, J.O., 2011. Egg mortality: predation and hydrography in the central Baltic. ICES J. Mar. Sci. 68 (7), 1379-1390.

Wieland, K., Waller, U., Schnack, D., 1994. Development of Baltic cod eggs at different levels of temperature and oxygen content. Dana J. Fish Mar. Res. 10, 163-177. 